\title{
Back to the Basics: A Process Approach for Managing Portfolio Risk
}

\author{
Ronald R. Mau \\ The Kimmel School, Western Carolina University \\ 211 Belk, Cullowhee, NC USA 28723 \\ Tel: 1-828-227-2544 E-mail: rmau@wcu.edu
}

\begin{abstract}
This paper examines the traditional views of risk in the finance and economics literature as applied to portfolio management. The paper demonstrates the inherent weaknesses in such approaches and suggests a process framework as a method for portfolio managers to manage risky situations. The framework incorporates seven considerations which may include both quantitative and qualitative factors which will affect the value of each consideration. The framework logically links the considerations to nine potential strategies for the management of a risky situation. The use of the framework provides a systematic approach to the management of a risky situation which should lead to improved performance.
\end{abstract}

Keywords: Risk Management, Portfolio Management, Investments

\section{Introduction}

Portfolio management involves investing capital in a variety of investment instruments and opportunities. The nature of the job involves decision making under uncertainty and risk. Risk can vary with various contexts; however, a systematic method which incorporates the calculative aspects of risk and the judgment of the portfolio manager can aid in the process of risk management and promote the development of knowledge through learning and development of tacit knowledge. Applying the learning and tacit knowledge and not strictly relying on computational risk management may prove a more effective method of managing risk.

Finance and specifically portfolio management (Markowitz, 1952) have typically used a minimum variance model to measure and manage risk. The goal is for zero variance around a benchmark. If the benchmark is the market return, the goal is to perform at the market level. The variance around a target implies risk is a two-sided phenomena with an upside risk and downside risk with the goal being to balance the poor returns with the good returns. "Upside risk" seems a rather odd concept. Investors would ideally prefer to avoid downside risk and earn all positive returns. "Upside risk" would be desirable and downside risk should be avoided.

Risk is an emergent phenomenon dependent on the complexity of a given situation. There is not a precise measurement possible for risk. For example, if one wishes to avoid poverty, a risk measure related to the potential for a large loss may be appropriate while if one wishes to demonstrate investment performance a measure related to a target return may be a more appropriate measure. There is no all encompassing measurement of risk yet the academic literature regarding financial risk continues to regard risk as a known variable that can be measured and manipulated. The attempt to measure and manipulate the unknown results in outcomes which demonstrate the problems of the theory. The use of computer models that calculate risk and derivatives to manage risk can result in false levels of security as demonstrated by the recent financial crisis.

The measurement and the manipulation of the unknown seems a rather odd pursuit. Are the theorists attempting to ask the epistemological question, "How do you know what you do not know?" This paper briefly describes the historical development of risk measures used in finance and economics to provide the reader with a background of how the field has arrived at the current state. To achieve this, a brief discussion of probability theories is provided for background and the development of risk measures by economists is provided.

Olsen (1997) surveyed portfolio managers to identify what investment professionals consider the key characteristics of risk. The factors considered by the portfolio managers are different than risk as identified in the finance/economic literature but consistent with concepts of risk in more general managerial situations. The paper then demonstrates how a general process framework for managing risky situations (Mackenzie, 1998) can be applied to portfolio management. Examples which apply the framework to hypothetical investment decisions a portfolio manager would make regularly are developed to demonstrate the usefulness of the process framework to portfolio risk management.

\section{The Basis of Risk Measurement: Probability Theories}

The fundamentals underlying the different concepts of risk are various probability theories. These different probability theories are: classical probability, relative frequency probability, logical probability, subjective probability and behavioral probability. Each is briefly described below (Weatherford, 1982). 
Classical Probability: The probability of an event is the ratio of the number of ways the event can occur to the total number of outcomes. Classical probability applies to games of chance such as games involving dice or cards.

Relative Frequency Probability: This probability of an event is the limit, as the number of trials increases, of the ratio of the number of times the event has occurred to the number of trials.

Logical Probability: Logical probability is the probability of an event's occurrence expressed as the degree of rational belief relative to the given information.

Subjective Probability: The probability of an event is the quantitative degree of individual belief in the event's occurrence.

Behavioral Probability: The probability of an event is the non-quantitative degree of individual belief in the event's occurrence.

\section{The Historical Development of Financial and Economic Risk Measures (Note 1)}

Prior to 1900 risk was primarily dealt with in the context of insurance. Edgeworth wrote one of the first articles applying probability theory to historical cash flows to estimate cash reserve requirements. Before the end of the 19th century, the relationship between probability and risk was being explored. Generally, the early applications were concentrated in the area of insurance and used relative frequency probabilities to develop risk measures. Relative frequency introduces issues to risk measurement which do not hold. In order to use relative frequency, a representative sample must be present to develop risk measures. Therefore, without relative frequencies risk would not be present; however, risk does exist when the statistical data does not. Relative frequency probability measures of risk require trials and statistics to develop the relative frequency probabilities; therefore, risk and relative frequency probabilities are not the same.

One of the most cited early discussions of risk is that of Frank Knight. Knight (1921) included risk and uncertainty in his work but he did not consider risk and uncertainty to be the same. According to Knight, uncertainty was not quantifiable. Risk was a known chance based on a known probability distribution while uncertainty deals with a subjective probability that is not known. According to Knight there exists some inherent "unknowability" for a given decision. Knight argued business decisions deal with such unique conditions that statistical data of relative frequencies although useful did not represent the "unknowable" outcomes of the future. "The business man himself not merely forms the best estimate of the outcome of his actions, but he is likely also to estimate the probability that his estimate is correct." (Note 2) Hence, there is an estimate of an estimate.

Subjective probabilities are those that are of economic interest, but developing frequency probabilities from unique conditions is not possible. Therefore, risk was usable for known distributions while uncertainty, dealt with the unknown. His objections to defining risk were relative frequency issues, law of large numbers and representative samples. Florence used a similar model of risk and discussed risk and uncertainty using three factors: the value of the probability, the theory of the probability, and the precision of the value where precision could be determined statistically or subjectively. Florence like Knight and others realized the "unknowable" factors inherent to risk.

Entering the 1930 's, probabilistic measures of risk had been rejected primarily because the belief was a probabilistic measure of risk was not appropriate for economic activity. Each situation was unique; therefore, no relative frequencies existed. The theoretic issues were too great to be ignored and required significant simplification. Knight and others did not agree with the omniscience required by the classical economists. There was thought to be no reference class and even if reference classes existed the law of large numbers eliminates risk if and when relative frequencies are stable.

However, this began to change in the late 1930's and early 1940's. During this time period there was an exodus of German and Austrian economists whose background was mathematics. They believed probability distributions based on relative frequencies were useful and provided a tool for the measurement of risk. The issues thought to have been too great to ignore by Knight and others were disregarded. This began the movement away from Knight's definition of risk and uncertainty. Since that period, risk has generally been measured using probability and statistical measures of dispersion. The issue with historical probability distributions is there is no such thing as a conclusive empirical test. The world involves infinite processes of which we have limited observations nevertheless risk measurement has proceeded as if complete knowledge is available. The orthodox economists proceed with the premise uncertainty has a minimal role because rational, utility maximizing individuals are able to eliminate the risk with the historical information at hand.

Arrow (1965) discusses the state of the world that if true and known all actions would be known. This state is related to a relative strength of belief in the occurrence of the different states of the world and these may vary from objective measurements. Arrow appears to understand some of the limitations but determines the way to proceed is to "face the questions and difficulties firmly and proceed." Nevertheless, probabilities based on relative frequencies are the preferred methodology in the finance field and have advanced new approaches to risk management. Extreme value 
theory has cultivated new risk management strategies and measurement techniques which model the tails of a probability distribution in a different manner.

The economic value of the different risk management strategies remains a question and these new approaches do not predict extreme events. Extreme value theory adds more complicated mathematical models to a distribution with the same limitations as before. The goal appears to become more precise at measuring a probability distribution which is not knowable. More complicated mathematics is being applied to the same problem which has the assumed problems as discussed previously. Complicated math does not cure the ills of the assumptions; the patient still has the same disease. These new high powered models would be consistent with the words of Malkiel in 1982:

"The quest for better risk measures is not simply an amusing exercise that accomplishes only the satisfaction of permitting academics to play with their computers. It has important implications for protecting investors."

\section{The Finance Domain and Limitations of Traditional Risk Measurement}

Relative frequency probabilities are used in the finance domain. Past events are used to develop a historical probability distribution which is used to determine the probabilities of future events. The inherent assumptions of relative frequency models as outlined by Frankfurter and McCoun (1996) are:

Historical relative frequencies can be interpreted as the probability of future events.

Future single events cannot be isolated.

Future events must be part of a series of events in order to have a numerical probability.

There is no information outside of the historical relative frequency of an event that is relevant to the estimation of the probability of the event.

These assumptions raise a number of questions such as relationships to reference groups. The use of reference groups assumes the historical events are the same as the future events. This implies the participants and conditions of the past will be repeated in the future. However, the participants change (learn) and the operating environment is different; therefore, there is not a true reference group for determining the probabilities to be used.

A second issue involves the implications implied by the law of large numbers. The law of large numbers states as the number of trials increases, the results should converge to the expected value with less deviation. As the number of trials approaches infinity the deviation around the expected value approaches zero. The mean is the expected value and the deviation or risk measurement is the standard deviation or variance. If an investor invests in an asset with an expected annual return of 15 percent and a standard deviation of 8 percent, and the holding period approaches a large number according to the law of large numbers the expected return should be equal to 15 percent. There will be some variance in the short term as indicated by the deviation measure. If an investor holds the referenced security for a long period the distribution would hold and returns would be 15 percent with some variation based on the statistical measures of the distribution. The application of the deviations focuses on the short term but is based on long-term data assumed to be stable enough to determine the deviation. If the model is stable enough to determine the deviation, a reasonable assumption would be the model is stable enough to determine the expected returns. The law of large numbers would imply a virtual elimination of the risk if the risk is held for a long period and the distribution is stable.

Relative frequency depends on the existence of a real distribution. However, will the behavior of the market participants in the future be predicted by the past? Will the external environment be duplicated in the future? Prior to September $11^{\text {th }}$, most people did not include a risk factor for a terrorist attack on U.S. soil yet the risk existed. The Enron debacle has introduced new risks for corporate governance issues and possible risk related to auditor selection (Peregrine among others). There was no historical data to predict such events, yet these events have had significant influence on the financial markets and insurance industry. More recently, the collapse of the housing market and issues with collateralized debt obligations have had a negative impact on financial markets despite complicated risk management tools. Strictly applying relative frequencies would not result in real distributions which include these events. Without the real distributions relative frequencies exist but the actual probabilities do not because of the unknown events.

These issues are not routinely raised in the finance and economics literature. Relative frequencies are developed and applied without question. However, as the historical discussion demonstrates this has not always been the case. The inherent problems were recognized by Knight 80 plus years ago and are difficult for the mathematics to calculate. The problems made the German-Austrian mathematician-economists mathematical models difficult to use and interpret. Therefore, the problems were disregarded and despite the same valid exceptions, economists have continued to use these models which are based on perfect knowledge and perfect rationality.

\section{The Application of the Theory}

The work solidifying the variance minimization approach in the field of finance and portfolio management is Markowitz's work (1952). Markowitz studied how investors construct portfolios and approached the issue as a 
normative study to understand whether investors' approaches were consistent about their beliefs of means, variances and covariance. However, the paper has been used as a positive study and has been used to develop CAPM and has extended portfolio theory despite many limitations. Markowitz himself concluded his work was a guide and provides a prescription under the following conditions: risk aversion, one time period, and an expected utility function that is quadratic. (Note 3)

Applying the theory would lead the portfolio manager to statistically determine the optimal portfolio by considering the beta coefficients and covariance of the investments in order to have a portfolio on the efficient frontier. Extreme applications of the theory would indicate a portfolio can be managed by considering the statistical characteristics of the past movements of the equities price. The extreme application of the theory would lead one to conclude the economic characteristics of the investment (i.e. what the firm makes, markets, and sells) are not the important components of the individual investment and the portfolio; what matters are past price movements and statistical measures of those price movements and some measure of the risk.

Traditionally, portfolio management theory has desired to minimize variance to some expected or target return with the benchmark most often considered to be the return of the S\&P 500. Strictly applying the theory, the intent would be to minimize the variance around the return of the S\&P 500. The return of the S\&P 500 is not a constant so the variance is minimized relative to a moving target which may be troublesome. Assuming the target is known (and fixed) and the theory is strictly applied, the returns should equal the returns of the market. Applied to a typical mutual fund, the investor will likely never see returns as great as the market return. For the investor, the return less expenses, management fees and the need for some cash for redemptions is left with returns below the goal of market return despite the fact the manger may have achieved the stated goal.

To our portfolio manager:

Thank you very much for disregarding the business of the businesses you hold in the portfolio. By applying your wonderful statistical models to the portfolio and reducing the risk associated with our investment you have guaranteed our investment a return of less than the market return. We will be forever grateful for your blind faith in a theory that despite its many limitations you have continued to implement.

Signed your investors.

The theory was developed making inferences from the data regarding the agent's behavior (the outcomes) and not directly observing the behavior. Therefore, when applying the theory to the extreme, as demonstrated above, the inherent weaknesses are exposed. As stated by Warren Buffett, "the academics' definition of risk is far off the mark, so much so that it produces absurdities." (Note 4)

\section{Portfolio Managers Key Risk Characteristics}

Olsen (1997) surveyed professional portfolio managers who had responsibility for institutional investment portfolios in order to develop an understanding of characteristics of risk considered important by investment professionals. The survey results indicate portfolio managers do not consider variance or large positive returns as important considerations of risk. According to the survey, the major risk characteristics for portfolio managers are:

a large loss (i.e. loss of principle large drop in price, negative return)

return below a target (i.e. downward price fluctuation, cut in dividend, nonpayment of interest)

knowledge (i.e. amount, quality, and timeliness of information about firm)

ability to control, particularly losses.

These results are similar to managerial views of risk in other domains. March and Shapira (1987) indicate managers do not treat uncertainty about positive outcomes as an important aspect of risk which is consistent with Olsen's findings dealing with portfolio managers. March and Shapira found managers believe risk is manageable and can be reduced by using skills to reduce the risk. Olsen's results discuss control as being important to the portfolio managers particularly with respect to avoiding losses and being able to take action to avoid losses. The portfolio manager's control the investments in the portfolio and use their judgment to manage the risks of the portfolio. Similar to March and Shapira findings, the portfolio managers believe risk is manageable as indicated in control representing an important characteristic of risk. Another similarity is managers look for alternatives to meet targets. The portfolio managers indicated not meeting a target return is an important attribute of risk. On a daily basis portfolio managers alter the holdings of the portfolio in an attempt to meet a target. Portfolio managers on a regular basis buy and sell securities with the objective being to meet a target which was identified as an important aspect of risk by respondents in Olsen's survey.

Olsen's results are similar to those of March and Shapira regarding the manager's concept of risk. These concepts are not entirely probabilistic as traditional finance and decision science theory would lead us to believe. There are tacit and 
intuitive processes affecting the risk management processes and strategies dealing with risk.

Olsen (2000) indicates investment professionals rely less on quantitative methods as predictability declines. Judgment becomes more important in volatile markets, in evaluating volatility and evaluating small firms. This judgment would be the result of experience and learning. According to the professionals, the quantitative methods are more appropriate when more information is available; however, as less information is available the tacit knowledge of the expert becomes more important in the risk considerations. Therefore, if tools are available to improve decision making in risky situations, learning can result, knowledge can result and better risk management strategies can be implemented in future risky situations.

\section{Managing Portfolio Risk in a Process Framework}

\subsection{The Risk Situation Framework}

Mackenzie (1998) introduces a comprehensive framework for managing risky situations which includes seven considerations and nine strategies. The systematic approach allows for consistent risk management, and learning due to the consistent approach. Figure 1 provides the model's framework.

(Insert Figure 1 about here)

The framework includes nine strategies for managing the risky situation. They are:

$\mathrm{s}_{1}=$ Do nothing

$\mathrm{s}_{2}=$ Retreat from the risky situation

$\mathrm{s}_{3}=$ Defensive coping

$\mathrm{s}_{4}=$ Exert power internally

$\mathrm{s}_{5}=$ Aggressive defense

$\mathrm{s}_{6}=$ Maneuver for personal advantage

$\mathrm{s}_{7}=$ Prospect for a lever in order to gain more internal control

$\mathrm{s}_{8}=$ Independent control of the sources of the risky situation

$\mathrm{s}_{9}=$ Strategic levering

The strategy chosen is not dependent on the activity of the market that day or the latest news event. The strategy will depend on the consistent application of seven considerations of the framework which offer the portfolio manager the flexibility to use their own judgment. The considerations are:

$\mathrm{c}_{1}=$ Is the entity aware that it is facing a risk event?

$\mathrm{c}_{2}=$ Is there significant risk?

$c_{3}=$ Is the risky situation avoidable?

$\mathrm{c}_{4}=$ What are the sources of the risky situation?

$c_{5}=$ What is the strength of the coupling of these sources?

$\mathrm{c}_{6}=$ Can the entity influence the external sources of the risky situation?

$c_{7}=$ Can the entity control the internal sources of the risky situation?

A brief description of each consideration is provided below. For a more complete development of the considerations and framework see Mackenzie (1998).

Each potential investment decision will represent some risk. Consideration $\mathrm{c}_{1}$, simply asks if the entity is aware of the risk and is a simply binomial result where:

$\mathrm{c}_{1}=1$ if yes,

$=0$ if no.

If the portfolio manager is not aware of the risk event, the strategy would be to do nothing.

The second consideration $\left(\mathrm{c}_{2}\right)$ defines significant risk which introduces a risk measure which could be analytical or subjective. Various risk measures could be used to define the significant risk where a significant risk is defined as a risk measure being above an acceptable threshold. The process framework allows for flexibility because the value of the risk measure may vary based on the conditions and context of the situation. If the risk measure is unacceptable to the portfolio manager, the risk would be significant. An example of a possible risk measure consistent with Olsen's survey results would consist of a downside risk measure or below target return measure. The risk significance can vary based on the calculation of the risk measure, the given situation and the individual portfolio manager. Another example may 
be the value or understanding of the underlying assets of a securitized instrument.

Consideration $\mathrm{c}_{3}$ asks whether a risky situation can be avoided. Controls could be used to place limits on the manger such as given percentages of the portfolios assets in one investment, if an investment becomes too risky the investment could be sold.

Considerations $\mathrm{c}_{4}$ and $\mathrm{c}_{5}$ are related (source of risky situation and strength of coupling of these resources) to interdependence, interdependence uncertainty and power. The purpose of this paper is not to define these terms. For a full explanation of these concepts see Mackenzie (1998). Interdependence exists if the actions of one part can affect and be affected by the actions of another part. Interdependence uncertainty relates to the relationships between two parties and the uncertainties within the relationship. Power is defined by Mackenzie as the effective control of interdependence.

Consideration $\mathrm{c}_{4}$ indicates the sources of interdependence uncertainty and can be represented by one of three results.

$\mathrm{c}_{4} \quad=2$ if there are both external and internal interdependence uncertainty $\quad=1$ if there is only external interdependence uncertainty $=0$ if there is only internal interdependence uncertainty.

Consideration $c_{5}$ indicates the strength of the coupling between the external interdependence uncertainty (E-IDU) and internal interdependence uncertainty (I-IDU).

$\mathrm{c}_{5} \quad=1$ if coupling between the E IDU and I-IDU is judged to be strong E-IDU and I-IDU is judged to be weak.

$=0$ if the coupling between the

Considerations $\mathrm{c}_{6}$ and $\mathrm{c}_{7}$ relate to the influence and control of external and internal sources of interdependence. Consideration $\mathrm{c}_{6}$ asks if the entity can influence the external sources of the risky situation and consideration $\mathrm{c}_{7}$ asks if the entity can control the internal sources of the risky situation.

$\mathrm{c}_{6} \quad=1$ yes the entity believes it can influence the E-IDU

$=0$ no

$\mathrm{c}_{7} \quad=1 \mathrm{yes}$, if the entity believes it can control its I-IDU

$=0$ no.

\subsection{Example: Portfolio Manager of Large Pension Fund}

In this example the risky situation is managed by the portfolio manager of a large pension fund which has been known to attempt to influence firms in which the fund has significant ownership. The situation involves an existing stock holding where management of the firm is attempting to adopt a policy detrimental to shareholders. In similar situations, the implementation of similar policies has resulted in loss of market value. An example would include the adoption of poison pills. The decision had been made previously to invest in the firm so the process framework had previously indicated the investment would be acceptable using the process framework. The context has changed based on a potential decision by the firm. The portfolio manager is aware of the risk in any investment; therefore $c_{1}$ would be a yes. The significance of the risk would be related to the risk measurement used by the manager. The manager determines that if the new policy is adopted by the shareholders there will likely be a significant drop in the market value of the firm. Therefore, there is significant risk and $\mathrm{c}_{2}$ is yes.

The next consideration is whether the risk is unavoidable. Obviously, the manager could sell the security. However, there will be tax consequences to the sale of the stock. The manager controls a large block of shares and liquidating a large block could also adversely affect the value of the current investment. In addition, except for the possibility of the new policy, the portfolio manager believes the prospects of the firm are good and the firm in its current condition represents an acceptable investment. Therefore, at this time the risk is considered unavoidable. The source of the risk in this situation is external due the firm's decision and internal due to the current determination the manager would prefer to continue to hold the investment. The manager has been successful in the past in influencing the outcomes of shareholder votes. Therefore, it is believed strong coupling $\left(c_{5}\right)$ is present. The manager also believes threatening to sell a large block of shares may affect management's decision; therefore, $c_{6}$ is yes. The control of internal sources $\left(c_{7}\right)$ is yes. Therefore the strategy is strategic leveraging, $s_{9}$.

To implement the strategy, the manger could take a position which offsets the current position and unwind the positions after the shareholders vote. If the vote results in a decision considered detrimental to shareholders the hedged position will increase in value proportionally to the loss in value of the original position. By implementing the strategy the risky situation is managed in such a way losses (if any) will be minimal.

For each of the considerations there was not an inclusive quantitative method for the decision involved in managing the risk. The outcome of the shareholders vote is not known; the manager would need to base that decision on past experience and knowledge of the shareholders. There would not be relative frequency probabilities to predict these future events; a subjective probability relying on the portfolio manager's expertise would be necessary to analyze the situation.

Sub processes would be present at each consideration used by the portfolio manager to determine the value of each consideration. These sub processes could be modeled to develop a framework for each consideration node and further 
unwrap the sub processes.

At each node, the factors considered are not usually determined by past price movements and beta coefficients. These statistical measures may come into play at some of the considerations such as $\mathrm{c}_{2}$. The statistical measures represent the easy portion of the risk management. Judgment is required at each node which would be based on the portfolio manager's experience, tacit knowledge and expertise. The use of a systematic method provides the framework for consistent approaches to management of risky situations.

\subsection{Example: Portfolio Manager of Small Fund}

The second example is a small portfolio manager who does not control a large enough block of shares to be in a position to influence a policy change similar as described above. In this case, the considerations would provide the same results for considerations $c_{1}, c_{2}, c_{3}$ and $c_{4}$. However, in this case the source of the risk is external, but the strength of the coupling is weak and the portfolio manager has no influence over the external source of the risk ( $\mathrm{c}_{6}=$ no). Unlike the above example, based on the prospectus and regulations of the fund and description of the fund's investment practices provided to investors, the manager can not invest in derivatives, short or hedge positions. The portfolio manager is required to invest in equities with long positions, hold bonds or cash. In this situation $\mathrm{c}_{7}$ is no and the resulting strategy is retreat from risk, $s_{2}$. The manager can control the uncertainty by selling the shares of stock held in the portfolio thus removing the risk of the potential market reaction to the policy change.

\subsection{New Investment Decision}

In this example, the portfolio manager is considering the purchase of stock in a firm previously not owned by the fund. Based on the recent past the firm has demonstrated tremendous earnings growth and the fundamentals appear to indicate continued appreciation in the stock price. As with any investment, the manager is aware there are risks involved. The risk involved does appear to be significant based on the manager's measure of risk which in this case the manger has elected to use the beta coefficient as the risk measure. For the firm under consideration, beta is 1.5 which is higher than the market beta of 1.0. Therefore, there is significant risk and $c_{2}$ is yes or 1. The portfolio owns stocks and each carries with them some risk. Risk is inherent to investing in equities and is unavoidable based on the prospectus of the fund, $c_{3}$ is yes or 1. In this example the risk is external and internal, $\left(c_{4}=2\right)$. The coupling is considered weak $\left(c_{5}=0\right)$. The fund is required to invest in equities and based on the risk measurement chosen the external risk is inherent to the firm and not influenced by the portfolio manager $\left(c_{6}=0\right)$. In this case, the manager has a large amount of cash that due to requirements of the fund must be invested in equities which the portfolio manager chooses to purchase. The manager controls the buy/sell decisions of the portfolio $\left(c_{7}=1\right)$ therefore, the resulting strategy is to exert power internally $\left(s_{4}\right)$. The manager can exert power internally by purchasing the stock. The risk in the portfolio is increased by the manager's judgment to invest in this firm, but the manager's judgment concludes the investment represents a great opportunity.

\section{Implications of the Process Framework to Portfolio Management}

In section six of this paper, the odd results that can occur due to the application of traditional portfolio management risk techniques were demonstrated. If the portfolio manager uses backward looking statistics, a complete understanding of the context and inherent risk is not realized. There is more to a risky situation than the pure mathematical manipulation of the distributions. Expertise of the portfolio manager is more than considering the past price movements. The portfolio manager must rely on intuition and experience in evaluating the given risky situation.

Implementing the process framework as demonstrated allows the manager to consider risk factors and methods to control risk in a variety of situations using the appropriate strategy. By using such a framework, the manager is allowed the flexibility to measure risk in manners the manager deems appropriate and include other factors for the scenario. Mackenzie (1998) claims using the framework develops greater expertise by: organizing relevant considerations into a coherent pattern, making predictions of what strategy will be chosen, comparing between actual observations and predictions to learn, using the framework iteratively to incorporate changes of in the value of the considerations, analyzing different conclusions due to the different values and focus of different entities, providing a checklist to control the process and assist the entity to make more comprehensive decisions, stimulate tacit knowledge by iterative use of the framework, devising strategies for altering the decisions of others by working backwards through the framework to determine what others consider to be the key consideration and improving expertise by tapping different members of the decision making process.

Shenoy (2001) interviewed financial analysts and portfolio managers. The interviews indicated looking backwards at past decisions is not done. There is reevaluating in attempt to learn from past failures and strategies implemented by the portfolio manager or financial analyst. A framework which assists and provides a tool to reevaluate will improve the process and risk management of the portfolio manger as demonstrated above in the simple examples.

\section{Conclusion}

The problem of relying on the quantification of risk has produced some undesirable outcomes. In this paper some of the 
issues related to the assumptions of quantifying risk and the resulting weaknesses have been discussed. Perhaps a more basic approach to each individual decision can be used to manage risk. As stated by Davidson:

"the economic system is moving through calendar time from an irrevocable past to an uncertain and statistically unpredictable future. Past and present market data do not necessarily provide correct signals regarding future outcomes. This means, in the language of statistics, that economic data are not necessarily generated by a stochastic ergodic process" (Note 7)

As portfolio managers have said, knowledge is important; however, complete knowledge is not possible which makes risk management for the portfolio manager critical. The way one can manage risk is by following a procedure and systematically applying the methodology to risky situations. By incorporating the process framework demonstrated here knowledge can be gained and risk management improved. The framework includes seven considerations which are linked to nine different strategies. The values of the considerations provide a framework which aids in implementing the proper risk management strategy.

This paper identified the issues and problems with traditional approaches to risk measures in finance and economics. Application of the theory was shown to provide odd results for the portfolio investors. As Thaler (1991) observes, "when economists restrict their investigations to those explanations consistent with the paradigm, to the exclusion of simpler and more reasonable hypothesis, the tool becomes a handicap". As demonstrated, by implementing the process framework, the portfolio manager could consider various aspects of the scenario which include quantitative as well as qualitative aspects of the risky situation. The consideration of the complete story will aid the portfolio manager in determining the appropriate risk management strategy and not strictly rely on computer models and risk quantification.

\section{References}

Arrow, K. J. (1965). Aspects of The Theory of Risk-Bearing. Helsinki.

Cunningham, L. A., ed. (2001). The Essays of Warren Buffett: Lessons for Corporate America. New York: Cardozo Law Review.

Davidson, P. (1982). Rational Expectations: a Fallacious Foundation for Studying Crucial Decision Making Processes. Journal of Post Keynesian Economics, 5, 182-198.

Fischhoff, B. (1981). Acceptable Risk. Cambridge: Cambridge University Press.

Florence, P.S. (1929) The Statistical Method in Economics and Political Science. New York: Harcourt, Brace and Co.

Frankfurter, G. M. \& McGoun, E. G. (1996). Toward Finance with Meaning, The Methodology of Finance: What it is and What it Can Be. Greenwich, Connecticut: JAI Press, Inc.

Greer, W. B. (2000). Ethics and Uncertainty. Northampton, MA: Edward Elgar.

Haugen, R.A. (1999). The New Finance, The Case Against Efficient Markets. Saddle River, New Jersey: Prentice Hall.

Knight, F.H. (1921). Risk, Uncertainty and Profit. New York: Harper and Row.

MacCrimmon, K.R. \& Wehrung, D. A. (1986). Taking Risks. New York: The Free Press.

Mackenzie, K.D. (1998). A Framework for Managing Risky Situation. The International Journal of Organizational Analysis, 6, 5-31.

Malkiel, B. (1982). Risk and Return: A New Look. In B.Friedman (Ed.), The Changing Role of Debt and Equity (pp.27-46). Chicago: University of Chicago Press.

March, J.G. \& Shapira, Z. (1987). Managerial Perspectives on Risk and Risk Taking. Management Science, 33, 1404 -1418 .

Markowitz, H. (1952). Portfolio Selection. Journal of Finance, 7, 77-91.

Markowitz, H. (1991). Foundations of Portfolio Theory. Journal of Finance, 46, 469- 477.

McGoun, E.G. (1995). The History of Risk "Measurement". Critical Perspectives on Accounting, 6, 511-532.

Olsen, R. A. (1997). Investment Risk: The Expert's Perspective. Financial Analysts Journal, 53, 62-66.

Olsen, R.A. (2000). Are Risk Premium Anomalies Caused by Ambiguity. Financial Analysts Journal, 56, 24-31.

Schwartz, H. (1998). Rationality Gone Awry? Decision Making Inconsistent with Economic and Financial Theory. Westport, Connecticut: Praeger Publishers.

Shenoy, C. (2001). A Description of Security Analysts Decision Making. Working Paper University of Kansas.

Thaler, R. (1991). Quasi Rational Economics. New York: Wiley.

Weatherford, R. (1982). Philosophical Foundations of Probability Theory. London: Routledge and Kegan Paul.

Zenios, S.A. (2001). Managing Risk, Reaping Rewards. OR/MS Today, December, 2001. 


\section{Notes}

Note 1. McGoun, E.G. (1995) provides a more complete description of the history

Note 2. Knight, F.R. (1921). Risk, Uncertainty and Profit. New York: Houghton Mid and Company.

Note 3. Schwartz, H. (1998). Rationality Gone Awry? Decision Making Inconsistent with Economic and Financial Theory. Westport, CT: Praeger Publishers.

Note 4. Cunningham, L. A., ed. (2001). The Essays of Warren Buffett: Lessons for Corporate America, New York: Cardozo Law Review.

Note 5. Davidson, P. (1982). Rational Expectations: a Fallacious Foundation for Studying Crucial Decision Making Processes. Journal of Post Keynesian Economics, 5, 182-198.

Selection of Strategies for Managing a Risky Situation (from Mackenzie 1998)

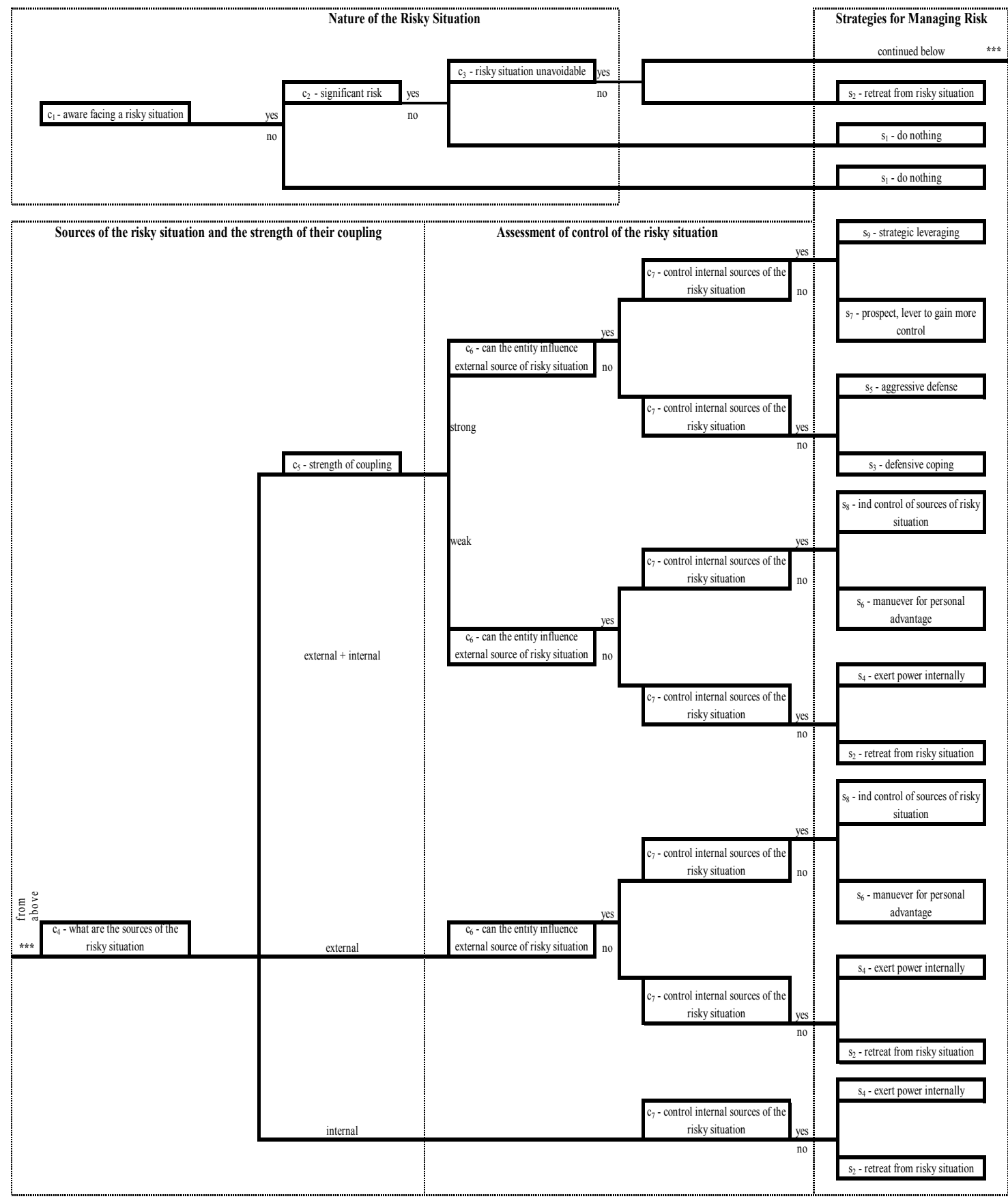

